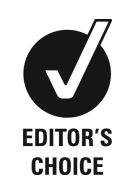

${ }^{1}$ Department of Anaesthetics, Royal Cornwall Hospital, Truro, UK

${ }^{2}$ Department of Trauma and Orthopaedics, Kingston Hospital Trust, Kingston upon Thames, UK

\section{Correspondence to} Dr Thomas Adam Cope, Tomcope@doctors.org.uk

Accepted 29 April 2015

\title{
Eye injuries in the extreme environment ultra-marathon runner
}

\author{
Thomas Adam Cope, ${ }_{1}^{1}$ Anna Kropelnicki ${ }^{2}$
}

\section{SUMMARY \\ We present the case of an ultra-marathon runner who developed a painful irritated eye due to prolonged exposure to high wind speed and sub-zero temperatures causing transient freezing and subsequent abrasion of the cornea. We recommend that all ultra-marathon runners racing in windy or exposed conditions should wear wrap-around eye protection or goggles. If runners present to checkpoints or after the race to primary care or the emergency department with ocular pain, corneal freezing and abrasions should be considered. Management should include ocular examination and withdrawing the runner from harmful conditions.}

\section{BACKGROUND}

Participation in long distance races and ultramarathons is rapidly increasing in popularity worldwide as athletes endeavour to challenge themselves with the mental and physical trials these races offer. The UK has seen a big rise in ultra races over varied terrain. ${ }^{1}$ Weather conditions add another dimension to these races. High wind speeds and cold temperatures may increase the attraction of certain races, but they present dangers to the participants which may not always be recognised. While the wearing of goggles is commonplace in winter activities such as skiing and mountaineering, it is less accepted as necessary by runners to prevent ocular injuries precipitated through prolonged exposure to high winds and sub-zero temperatures. There is very little evidence in the literature concerning the risk of eye injury or 'wind-blindness' in athletes, although it appears to be a well-known condition across running and ultra-marathon communities.

We present the first documented case of ocular injury in an ultra-marathon runner caused by prolonged exposure to high wind speeds and near-zero temperatures during a race in the UK, the evidence behind this injury and protective strategies.

\section{CASE PRESENTATION}

A 44-year-old male ultra-runner presented to the medical checkpoint at the end of the first stage of a 7-day non-stop ultra-marathon having completed approximately 47 miles. The patient is an experienced ultra-runner, having competed in long distance events around the world including the Lakeland 100, the Yukon 100 and the Yukon 450 races. He has also trained in mountain survival and cold weather survival techniques in preparation for races held in extreme environments, such as the
Arctic, and averages around 50 miles a week in training.

Upon arrival at the checkpoint, the patient complained of a sore left eye, with decreased acuity, 'cloudy' vision, and the sensation of having a foreign body in his eye. These symptoms had been present for a few hours. He reported that he had found navigation in the dark particularly difficult and frequently found himself missing his footing. Several other runners reported similar problems in their left eyes, with descriptions of tearing, itching and blurred vision being common, along with difficulty navigating and issues with depth perception. The patient had not been wearing goggles during the race and had no facial protection such as a peaked cap. He had no history of previous eye injuries or surgery, and he had not been wearing contact lenses. His previous acuity had been normal. He remarked that he had not had any problems with general or ophthalmic health in previous ultra-races including races held in extreme cold.

The prevailing weather conditions were westerly winds forecast to be in excess of 80 miles an hour on the exposed ridges of the route, heading predominantly north. The temperature had been forecast to be below $5^{\circ} \mathrm{C}$ for much of the day, with wind chill decreasing this to below zero with intermittent snow and hail throughout the day.

Examination of the eyes highlighted an abnormal left eye demonstrating some photosensitivity with the right eye appearing normal. The left eye appeared generally cloudy, with several small areas of more dense opacity (most notable at 7 o'clock as seen in figure 1).

Pupillary reflexes to light were intact in both eyes, and ocular movements were all intact. Visual acuity was subjectively worse in the left eye, with

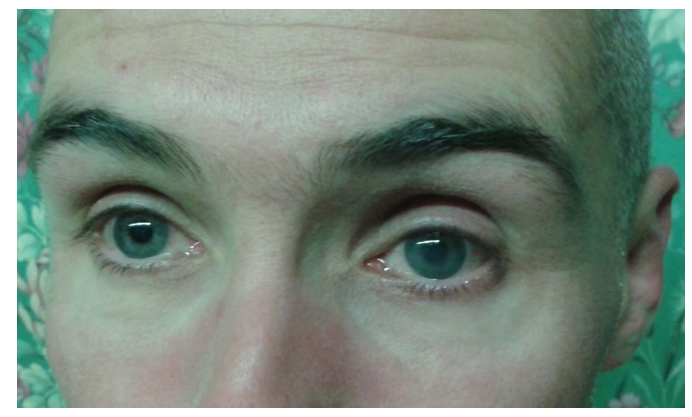

Figure 1 The left eye appears generally cloudy, with several small areas of more dense opacity (most notable at 7 o'clock). 
acuity restricted to finger counting at $3 \mathrm{~m}$. Acuity in the right eye was normal. Visual fields were grossly normal in both eyes, although testing was difficult in the left eye due to the significantly reduced acuity.

\section{DIFFERENTIAL DIAGNOSIS}

The left eye appeared to show tearing and the cornea generalised oedema accounting for the poor acuity along with several areas of corneal abrasion, accounting for the sensation of itchiness and photosensitivity.

\section{DISCUSSION}

Multi-day outdoor events and ultra-marathons across the world are rapidly increasing in popularity, and often take in a wide range of terrain and weather conditions. While musculoskeletal injuries are a recognised cause of morbidity in athletes, there appears to be little in the literature regarding ocular injuries caused by prolonged periods of time in adverse weather conditions. The majority of complaints among the runners in our race were of eye itchiness, soreness, tearing, photosensitivity and decreased acuity. Since the runners spent the most of the day with the prevailing wind to their left, the complaints were nearly all of left eye problems.

The injury in our patient appeared to consist of widespread corneal abrasion in the eye exposed to high winds and probably sub-zero temperatures. Traumatic corneal freezing and keratitis has been shown when the eye is exposed to such conditions. $^{2}$ These injuries have been seen in mountaineers and parachutists. ${ }^{3}$ The presentation is often a painful eye, light sensitivity and eyelid spasm, ${ }^{4}$ as seen in our case. Corneal injury should be considered in people complaining of these symptoms following exposure to high wind speeds and cold temperatures.

The pathology of such injuries appears to be a result of transient freezing of the corneal epithelium, confounded by particles carried into the eye by the wind such as snow or hail. The corneal epithelium is covered by a thin layer of tears that provide moisture to the epithelium, as well as offering some protection against foreign bodies. High winds dry the front of the eye and reduce the protection offered by disrupting the tear film. ${ }^{5}$ Insufficient lid closing also reduces protection against high winds, leading to dessication keratitis, and eventually corneal abrasion and ulceration. ${ }^{2}$ Kolstad and Opsahl ${ }^{5}$ noted in their report on corneal injury in cross-country skiers that insufficient lid closing resulted from lower tissue temperature causing decreased muscle contraction of the orbicularis occuli. They also noted that the extreme visual attention decreasing the palpebral fissure may have been a contributory cause, which would certainly be the case when navigating in the dark (as exemplified in this race). This drying and abrasion of the cornea may have led to the eye injury seen in our runner. Research has shown that another process may underlie the corneal injury. Gruppo et $a l^{2}$ investigated injuries in military parachutists whose eye protection had failed during free fall during which time their eyes were exposed to wind speeds of up to 170 miles per hour and sub-zero temperatures. Soldiers who lost their goggles showed temporary corneal damage due to desiccation of the epithelium and temporary freezing of the cornea, with a 30-fold increase if the cornea was exposed to sub-zero temperatures. While our competitors were not exposed to this level of wind speed, the winds were forecast to be upwards of 80 miles per hour on the day. Daley ${ }^{6}$ noted the negative effects of freezing corneas during the Iditarod Trail race and proposed a system for categorising corneal frostbite, ranging from superficial damage through to third degree corneal frostbite. Superficial corneal frostbite involves freezing of the water in the superficial layer of the epithelium, with rapid resolution and no permanent damage when the eye returns to above-zero temperatures. Due to the warming of the corneas when the patient is removed from the cold environment, when examined it is likely that the cornea is no longer frozen but inflamed and swollen, accounting for the appearance that we observed (figure 1).

Our patient described this injury as 'silent damage' occurring during the race. While racing he felt no pain or damage to the eye and did not recognise the risk until too late, similar to the experience of frostbite. Initially he had assumed the loss of depth perception and increased stumbling was due to fatigue and low blood sugar. It was not until he sought our help at the checkpoint that he realised it was a primary problem with his vision.

A frozen cornea is treated by removing the patient from the environment and avoiding any further exposure to wind or cold temperatures. The eye must be examined and the underside of the eyelids exposed to check for foreign bodies. Topical antiinflammatories, such as $0.1 \%$ diclofenac, have been used to reduce swelling and prophylactic anti-bacterial topical preparations such as chloramphenicol. In our case, we withdrew the runner from the race to avoid further damage to the cornea such as ulceration, which can ultimately threaten vision if left untreated.

\section{Learning points}

- Ocular pain in distance runners should be taken seriously.

- Eye protection should be considered mandatory in extreme environments regardless of the sport.

- Early recognition and protection can prevent progression of damage.

Acknowledgements We would like to thank the patient for his consent and valuable insights on his injury from an athlete's perspective.

Contributors TAC wrote the manuscript. AK sought consent from the patient, critically analysed the manuscript and made corrections.

Competing interests None declared.

Patient consent Obtained.

Provenance and peer review Not commissioned; externally peer reviewed.

\section{REFERENCES}

1 Cejka N, Rüst C, Lepers $R$, et al. Participation and performance trends in 100-km ultra-marathons worldwide. J Sports Sci 2014;32:354-66.

2 Gruppo L, Mader TH, Wedmore I. Occular problems in military free fall parachutists. Mil Med 2002;167:797-800.

3 Ansari I, Canning C. Frozen corneas in the desert: a case report. Grand Rounds 2012;12:6-9.

4 Ellerton JA, Zuljan I, Agazzi G, et al. Eye problems in mountain and remote areas: prevention and on site treatment-official recommendations of the International Commission for Alpine Rescue Commission for Mountain Emergency Medicine (ICAR MEDCOM). Wilderness Environ Med 2009;20:169-75.

5 Kolstad A, Opsahl R Jr. Cold injury to corneal epithelium, a cause of blurred vision in cross-country skiers. Acta Ophthalmol (Copenh) 1969;47:656-9.

6 Daley R. Frozen corneas - treatment in an ultra-cold climate. ASCRS EyeWorld, July 2004. http://www.eyeworld.org/article.php?sid=408\&strict=\&morphologic= \&query=ophthalmology 
Copyright 2015 BMJ Publishing Group. All rights reserved. For permission to reuse any of this content visit http://group.bmj.com/group/rights-licensing/permissions.

BMJ Case Report Fellows may re-use this article for personal use and teaching without any further permission.

Become a Fellow of BMJ Case Reports today and you can:

- Submit as many cases as you like

- Enjoy fast sympathetic peer review and rapid publication of accepted articles

- Access all the published articles

- Re-use any of the published material for personal use and teaching without further permission

For information on Institutional Fellowships contact consortiasales@bmjgroup.com

Visit casereports.bmj.com for more articles like this and to become a Fellow 